\section{SAT0160 EFFECT OF PERIODONTAL TREATMENT ON E- SELECTIN LEVEL IN RHEUMATOID ARTHRITIS PATIENTS}

S. A. Kusumo ${ }^{1}$, H. Isbagio ${ }^{1}$, S. Marhamah ${ }^{2}$, C. Intan $^{2}$, D. Antono ${ }^{1}$, K. Harimurti ${ }^{1}$. ${ }^{1}$ Department of Internal Medicine, Cipto Mangunkusumo Hospital/Faculty of Medicine, Universitas Indonesia, ${ }^{2}$ Department of Oral Medicine, Cipto Mangunkusumo Hospital, Jakarta, Indonesia

Background: Cardiovascular (CV) disease is the main cause of mortality in rheumatoid arthritis (RA). ${ }^{1}$ Studies showed that periodontitis is associated with RA and CV diseases..$^{2-4}$ Endothelial dysfunction is the first step in the pathogenesis of atherosclerosis. E-selectin is a marker of endothelial dysfunction and was expressed specifically in endothelial cells. To date, there is no study on the effect of periodontal treatment on endothelial dysfunction in RA patients.

Objectives: To determine the effect of periodontal treatment on E-selectin level in RA patients.

Methods: This was a clinical trial in RA patients visiting Rheumatology Clinic in our hospital between March-May 2017. Inclusion criteria: adult RA patients, has periodontitis, low-high RA disease activity, RA duration of 10 years or less, has received DMARD. Exclusion criteria: subjects who smoke, have diabetes, underwent dental treatment for the past 3 months, have other autoimmune diseases, and patients who refused to join the study. Subjects was randomized into intervention group (periodontal scaling for 1 month) and control group. Study flow is visualized in figure 1. E-selectin level was measured at the start and at the end of the study. T-test was used to measure the difference of E-selectin level changes before-after study between groups.

Results: There were 31 subjects who completed the study. The prevalence of periodontitis was $64.5 \%$. There was no statistically significant difference on delta E-selectin before-after treatment between both groups (table 1). We further divided the subjects based on disease activity and lipid profile at the end of the study. Subjects on the treatment group who was on remission and has normal lipid profile (normal LDL and decreased total cholesterol/HDL ratio) has decreased Eselectin level compared to other subjects.

Table 1 Study subjects and intervention

\begin{tabular}{llll}
\hline Characteristics & $\begin{array}{l}\text { Total }(\mathbf{n}= \\
\mathbf{3 1})\end{array}$ & $\begin{array}{l}\text { Intervention } \\
\text { group }(\mathbf{n}=\mathbf{1 7})\end{array}$ & $\begin{array}{l}\text { Control group } \\
(\mathbf{n}=\mathbf{1 4})\end{array}$ \\
\hline Age (years, mean \pm SD) & $55,4 \pm 8,8$ & $52,6 \pm 9,6$ & $58,9 \pm 6,4$ \\
RA duration (months, mean \pm SD) & $68,8 \pm 36,5$ & $57,8 \pm 36,5$ & $83,5 \pm 32,3$ \\
Disease activity(n, \%) & 16 & $10(58,3 \%)$ & $6(37,5 \%)$ \\
- Low & $(53,3 \%)$ & $6(35,3 \%)$ & $8(53,8 \%)$ \\
- Moderate & 14 & $1(3,3 \%)$ & $0(0 \%)$ \\
- High & $(43,3 \%)$ & & \\
& $1(3,3 \%)$ & & \\
Taking glucocorticoid (n, \%) & 20 & $12(70,6 \%)$ & $8(57,1 \%)$ \\
& $(64,5 \%)$ & & $24,92 \pm 2,86$ \\
BMI (kg/m ${ }^{2}$, mean $\left.\pm S D\right)$ & $24,9 \pm 3,17$ & $24,89 \pm 3,47$ & $0,82(0,2-3,2)$ \\
Oral Hygiene Index (median, min-max) & $0,85(0,14$ & $0,8(0,14-2)$ & \\
& $-3,2)$ & & $-2,7 \pm 9,7(p$ \\
Delta of E-selectin level start-end of & - & $-6,3 \pm 9,3$ & value 0,303$)$ \\
study (ng/mL, mean $\pm S D)$ & & &
\end{tabular}

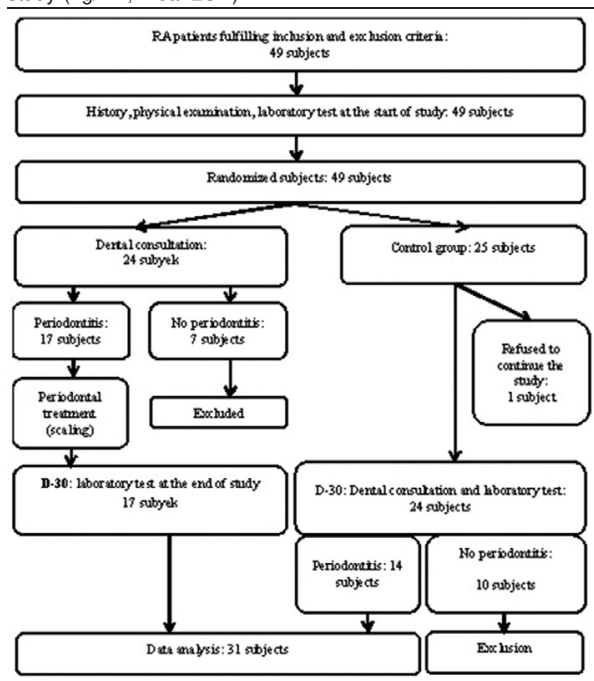

Conclusions: Periodontal treatment for a month has no effect on E-selectin level in RA patients. Further studies on the effect of periodontal treatment on endothelial dysfunction in RA patient needs to be done on patients on remission, without dyslipidemia, and with longer treatment period.
REFERENCES:

[1] Zochling J, Braun J. Clin Exp Rheumatol 2009;27(Suppl.55):S127-30.

[2] Chou YY, Lai KL, Chen DY, et al. PLoS ONE 2015;10(10):e0139693.

[3] Leng WD, Zeng XT, Kwong JSW, et al. Int J Cardiol 2015;201:469-72.

[4] Abou-Raya S, Abou-Raya A, Naim A, et al. Clin Rheumatol 2008;27 (4):421-7.

Disclosure of Interest: None declared DOI: 10.1136/annrheumdis-2018-eular.6244

\section{SAT0161 INFLUENCE OF DISEASE ACTIVITY IN RHEUMATOID ARTHRITIS ON RADIOGRAPHIC PROGRESSION OF CONCOMITANT INTERPHALANGEAL JOINT OSTEOARTHRITIS}

C. Lechtenboehmer ${ }^{1}$, V. Jaeger ${ }^{2}$, D. Kyburz ${ }^{2}$, U. A. Walker ${ }^{2}$, T. Hügle ${ }^{3} .{ }^{1}$ Radiology, ${ }^{2}$ Rheumatology, University Hospital Basel, Basel, ${ }^{3}$ Rheumatology, University Hospital Lausanne, Lausanne, Switzerland

Background: The role of inflammation in in distal interphalangeal (DIP) osteoarthritis $(\mathrm{OA})$ is not clear. Unlike the situation in psoriatic arthritis, DIP joints are considered not to be affected in rheumatoid arthritis (RA). Despite synovitis and bone marrow edema are also associated with radiographic progression of hand $O A$, the radiological course of DIP-OA and joints affected from RA differ substantially.

Objectives: To clarify the influence of RA disease activity and bone erosions on radiologic progression of DIP joint OA.

Methods: In sequential radiographs of 1988 RA patients available within the Swiss rheumatic disease registry (SCQM), we scored 15904 DIP joints for the presence of erosions as well as the severity of osteophytes, subchondral sclerosis and joint space narrowing according to the modified Kellgren Lawrence Grade (KLG). Progression was defined as an increase of KLG.

Results: The mean patient age was 56.1 years (SD 11.1). The median follow-up time was 4.5 years (IQR $3.1-7.0$ ). DIP-OA was present in $60 \%$ of patients at baseline. Age, female sex and higher body mass index but not anti-citrullinated protein antibodies or rheumatoid factors were associated with the presence of DIP-OA. Preexisting DIP-OA (odds ratio [OR] 4.7, $\mathrm{p}<0.001$ ) and female sex (OR $1.4, p=0.009$ ) were predictors for radiologic progression, whilst metacarpophalangeal joint erosions or DAS28-ESR had no influence on the radiological course of DIP-OA.

Conclusions: Known risk factors for DIP-OA are replicated in patients with RA. RA disease activity, autoantibody status or metacarpophalangeal joint erosions where not associated with DIP-OA presence or progression, indicating distinct roles of inflammation in the pathogenesis of RA and OA.

Disclosure of Interest: None declared

DOI: 10.1136/annrheumdis-2018-eular.1066

\section{SAT0162 WHERE SHOULD WE SEEK FOR SUBCLINICAL SYNOVITIS USING ULTRASOUND IN RHEUMATOID ARTHRITIS?}

W. Hamdi ${ }^{1}$, M. Sellami ${ }^{1}$, H. Riahi ${ }^{2}$, D. Kaffel ${ }^{1}$, K. Maatallah ${ }^{1}$, M. Chelli-Bouaziz ${ }^{2}$, M. F. Ladeb ${ }^{2}$, M. M. Kchir ${ }^{1} .{ }^{1}$ Rheumathology, ${ }^{2}$ Radiology, Kassab Orthopedics Institute, Manouba, Tunisia

Background: The role of ultrasound imaging (US) in rheumatoid arthritis (RA) management is fundamental by sharpen diagnosis, predicting prognosis, monitoring disease activity and identifying remission. The detection of subclinical synovitis and articular inflammatory changes represent the real advantages of this technology. However, joint US is time-consuming, thus identifying the area of subclinical synovitis should be useful to overcome this difficulty.

Objectives: We aimed to assess the most profitable joint locations in detecting subclinical synovitis in RA.

Methods: We performed a cross-sectional study of one hundred patients with inflammatory joint pain or synovitis for more than 6 weeks and less than 2 years. All patients were free of conventional or biological DMARD's at inclusion. An experienced radiologist performed the MSUS scan of 22 joints (2 wrists, 10 metacarpophalangeal joints MCP and 10 proximal interphalangeal joints PIP) unaware of clinical and biological findings. MSUS was performed using a Philips HD11. The used frequency ranged from 15 to $17 \mathrm{MHz}$ and we used a Power Doppler (PD). After US assessment, patients were classified as having RA according to ACR/EULAR 2010 criteria.

Results: We enrolled 100 patients ( 77 women and 23 men) with a mean age of 51.8 years [16-77]. Fifty-five patients (55\%) fulfilled the ACR/EULAR 2010 criteria for the diagnosis of RA. The mean disease duration was 10.96 months [2-24]. Rheumatoid factor and ACPA were positive in $53 \%$ and $25 \%$ cases respectively. The mean disease activity score at the time of study was 5.36 [1.36-8.61]. A clinical wrist synovitis was found in 92 cases $(46 \%)$. In the 54 wrists with no clinical 
synovitis, a total number of US wrist synovitis was detected at $30(15 \%)$ radioulnar (of which half was Doppler +), $91(45.5 \%)$ radiocarpal (of which 60\% was Doppler +) and 105 (52.5\%) intercarpal joints (of which 67\% was Doppler +). Concerning the MCP and PIP joints, the most frequent location of subclinical synovitis were 1 st MCP in 51 cases $(25.5 \%)$, 4th MCP in 49 cases $(24.5 \%)$, 5th MCP in 50 of cases $(25 \%), 1$ st PIP in 24 cases (12\%) and 5 th PIP in 22 cases (11\%).

Conclusions: Our study highlighted the low sensitivity of physical examination of synovitis in hand and wrist joints, especially in some locations. We showed the most frequent location for detecting subclinical synovitis were radiocarpal and intercarpal joint, 1st-4th -5th MCP and 1st-5th PIP. About half of those subclinical synovitis were Doppler +.

Disclosure of Interest: None declared

DOI: 10.1136/annrheumdis-2018-eular.5546

\section{SAT0163 ABSOLUTE NUMBER OF PERIPHERAL CD4-CD25 +FOXP3+T CELLS DECREASES AND RESTORES AFTER LOW-DOSE INTERLEUKIN-2 TREATMENT IN RHEUMATOID ARTHRITIS}

X. Jia ${ }^{1}$, H. An ${ }^{1}$, K. Fan ${ }^{1}$, F. Li ${ }^{1}$, C. Gao ${ }^{2}$, X. Li ${ }^{1} .{ }^{1}$ Rheumatology, The Second Hospital Of Shanxi Medical University, Taiyuan, China, ${ }^{2}$ Pathology, Brigham and Women's Hospital, Boston, United States

Background: Recently, several studies have suggested that abnormal quantity and function of regulatory $T$ cells (Tregs) may play a vital role in the development of rheumatoid arthritis (RA). CD25+FOXP3 ${ }^{+}$T cells include $\mathrm{CD}^{+}\left(\mathrm{CD} 4^{+}\right.$Tregs) and $\mathrm{CD}^{+}$cells $\left(\mathrm{CD} 8^{+}\right.$Tregs). Recently studies have shown that $\mathrm{CD} 8^{+}$Tregs also have immunosuppressive function, similar to even stronger than $\mathrm{CD} 4^{+}$Tregs, and are more sensitive to IL-2 in vivo. However, the status of CD8+Treg cells in RA is unknown.

Objectives: Our study was designed to clarify the level of CD4 $4^{-} \mathrm{CD} 25^{+} \mathrm{FOXP} 3^{+} \mathrm{T}$ cells in RA patients, and to investigate the role of low-dose interleukin-2 (IL-2) therapy in the regulation of $\mathrm{CD} 4^{-} \mathrm{CD} 25^{+} \mathrm{FOXP} 3^{+} \mathrm{T}$ cells in RA patients to provide another theoretical basis besides CD4 ${ }^{+}$Tregs to IL-2 therapy.

Methods: Three hundred and four RA patients (diagnosis according to the 2010 ACR criteria) were enrolled; no treatment group $(\mathrm{N}=75)$, DMARDs treatment group $(\mathrm{N}=73$ ), low dose IL-2 treatment group (50WIU/day $\times 5$ days, subcutaneous injection) $(N=156)$, and healthy control group $(N=90)$. The absolute numbers of $\mathrm{CD}^{-} \mathrm{CD} 25^{+} \mathrm{FOXP3}{ }^{+} \mathrm{T}$ cells in peripheral blood were detected by flow cytometry. We assumed that $\mathrm{CD} 4^{-} \mathrm{T}$ cells with $\mathrm{CD} 25^{+}$and $\mathrm{FOXP3}^{+}$were mostly $\mathrm{CD}^{+}{ }^{+} \mathrm{CD} 25^{+} \mathrm{FOXP}^{+}$Treg cells, which was $\mathrm{CD}^{-} \mathrm{CD}^{-} 5^{+} \mathrm{FOXP}^{+} \mathrm{T}$ cells in this study. The levels of $\mathrm{CD} 4^{-} \mathrm{CD} 25^{+} \mathrm{FOXP} 3^{+} \mathrm{T}$ cells among these groups were compared with that of health group or each other respectively, and then the statistical software SPSS 20.0 was used for analysis; $p<0.05$ was considered significant. Results: As compared with the healthy group, the absolute number of $\mathrm{CD}^{-} \mathrm{CD}^{2} 5^{+} \mathrm{FOXP}^{+} \mathrm{T}$ cells decreased significantly in the untreated RA patients $[0.94(0.41,1.61)$ vs $1.31(0.72,2.52), P<0.001]$ and more dramatically in DMARDs treatment patients $[0.86(0.36,1.83)$ vs $1.31(0.72,2.52), \mathrm{P}<0.01]$. After treatment with IL-2, the absolute count of $\mathrm{CD} 4^{-} \mathrm{CD} 25^{+} \mathrm{FOXP} 3^{+} \mathrm{T}$ cells increased significantly compared with that before treatment $[0.91(0.48,1.54)$ vs $2.10(1.12,3.56)$, $\mathrm{P}<0.001]$.
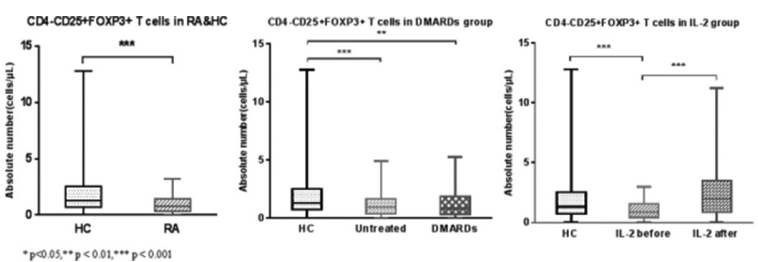

Conclusions: The absolute number of $\mathrm{CD} 4^{-} \mathrm{CD} 25^{+} \mathrm{FOXP} 3^{+} \mathrm{T}$ cells in untreated RA patients were lower than those health, implying that $C D 4 C D 25^{+} \mathrm{FOXP3}^{+} \mathrm{T}$ cells deficiency was caused by disease itself but not immunosuppressive therapy, which may be an important factor in the pathogenesis of RA. The traditional DMARDs therapy did not improve this reduction. Low dose IL-2 can increase the absolute number of $\mathrm{CD}^{-} \mathrm{CD} 25^{+} \mathrm{FOXP3}{ }^{+} \mathrm{T}$ cells in peripheral blood. We are about to detect the number of $\mathrm{CD}^{+} \mathrm{CD} 25^{+} \mathrm{FOXP} 3^{+}$Treg cells accurately to verify this theory.

Disclosure of Interest: None declared

DOI: 10.1136/annrheumdis-2018-eular.4123

\section{SAT0164 \\ ADVERSE DRUG REACTIONS DUE TO DISEASE MODIFYING DRUGS IN PATIENTS WITH INCIDENT RHEUMATOID ARTHRITIS}

Z. Rosales Rosado ${ }^{1,2}$, D. D. Freites NÚÑEZZ2, C. Lajas Petisco ${ }^{1}$, E. Pato Cour ${ }^{1}$, L. León Mateos ${ }^{2}$, L. Abásolo Alcázar ${ }^{2}{ }^{1}$ Rheumatology, hospital clínico san carlos,

${ }^{2}$ Instituto De Investigación Sanitaria San Carlos, Madrid, Spain

Background: There is a well-known risk of developing adverse drug reactions $(A D R)$ in rheumatology due, mainly, to the Disease Modifying Antirheumatic Drugs (DMARD) used. There is no doubt about their efficacy in Rheumatoid Arthritis (RA), but it is necessary to increase our knowledge of their ADR, especially those that lead to discontinuation

Objectives: To describe the incidence and characteristics of ADR related with DMARD in patients with incident RA as well as the factors involved in their development

Methods: Observational retrospective longitudinal study between April 15th 2007 and December 31st 2016. Inclusion criteria: patients diagnosed with RA between April 15th 2007 and June 31st 2011 followed until December 31st 2016 whom started any DMARD. Primary endpoint: development of an ADR that required discontinuation of the DMARD (moderate: discontinuation; severe: discontinuation with hospitalization or death). Co-variables: sociodemographic; clinical and therapy. Statistical analysis: incidence rates of discontinuation (IR) per 100 patient-years were estimated using survival techniques with their respective $95 \%$ confidence interval $[\mathrm{Cl}]$. Comparisons between associated factors were run by Cox bivariate and multivariate regression models. Results were expressed by hazard ratio $(\mathrm{HR})$ and $[\mathrm{Cl}]$

Results: We included 1054 courses of DMARD treatment in 405 patients (2277.9 patient-years). $78.3 \%$ were women with a mean age at diagnosis of 57 \pm 15 years. During follow-up, $16.3 \%$ of patients were taking biological DMARD, $73.3 \%$ were using monotherapy and $89 \%$ were taking corticoids. There were 369 ADR in 212 patients, $88.9 \%$ moderate. Gastrointestinal was the most frequent cause of ADR (26.3\%), followed by infections (12.2\%). IR are shown in table 1 and the multivariate analysis in table 2. Regarding type of DMARD, Abatacept had the highest risk of ADR development (HR:4.9[2.1-11.2]) compared to the other drugs followed by Gold (HR:1.6[1-2.6]) and Leflunomide (HR:1.4[1.1-1.9]). Methotrexate was the safest drug compared with the others $(0.6[0.5-0.8])$

\begin{tabular}{lllll} 
Table 1 & & & & \\
\hline Global & 2277.9 & 369 & 16.2 & $14.6-17.9$ \\
Women & 1835.4 & 296 & 16.1 & $14.4-18.1$ \\
Men & 442.5 & 73 & 16.5 & $13.1-20.7$ \\
\hline By therapy & 1609.5 & 200 & 12.4 & $10.8-14.3$ \\
regimen & 568.9 & 132 & 23.2 & $19.6-27.5$ \\
Monotherapy & 99.4 & 37 & 37.2 & $26.9-51.4$ \\
Double therapy & & & & \\
Triple therapy & & & & \\
By type of DMARD & 2048.3 & 326 & 15.9 & $14.3-17.7$ \\
Synthetic & 229.5 & 43 & 18.7 & $13.9-25.3$ \\
Biological & & & & \\
By drug & 8.3 & 5 & 60.6 & $25.2-$ \\
Abatacept & 81.5 & 10 & 12.3 & 145.5 \\
Adalimumab & 749.7 & 157 & 20.9 & $6.6-22.8$ \\
Antimalarials & 19 & 3 & 15.7 & $17.9-24.5$ \\
Azathioprine & 16 & 4 & 24.8 & $5.1-48.8$ \\
Certolizumab & 65.2 & 12 & 18.4 & $9.3-66.2$ \\
Etanercept & 9.1 & 5 & 54.9 & $10.5-32.4$ \\
Golimumab & 18.4 & 6 & 32.7 & $22.9-$ \\
Infliximab & 340.4 & 85 & 25 & 131.9 \\
Leflunomide & 1463.5 & 206 & 14.1 & $14.7-72.7$ \\
Methotrexate & 83.6 & 33 & 39.5 & $20.2-30.9$ \\
Gold & 26.3 & 1 & 3.8 & $12.3-16.1$ \\
Rituximab & 154 & 45 & 29.2 & $28-55.5$ \\
Sulfasalazine & & & & $0.5-27$ \\
& & & & $21.8-39.1$ \\
\hline & & &
\end{tabular}

Table 2

\begin{tabular}{llll}
\hline Monotherapy & 1 & - & - \\
Double therapy & 2 & $1.5-$ & 00 \\
Triple therapy & 4.2 & 2.5 & \\
& & $2.6-$ & \\
& & 6.8 & 0.002 \\
\hline Congestive heart & 1.8 & $1.2-$ & \\
failure & & 2.7 & 0.012 \\
Liver disease & 2 & $1.2-$ & \\
& & 3.3 & \\
\hline
\end{tabular}

